\title{
0983 PREVENTING SEXUAL VIOLENCE TO YOUNG WOMEN AND CHILDREN
}

R Proops*, D Rees* Correspondence: World Health Organization, Institute of Work, Health and Organisations (I-WHO), University of Nottingham, International House, Jubilee Campus, Wollaton Road, Nottingham NG8 1BB, UK

\subsection{6/ip.2010.029215.983}

Sexual violence against children represents a major public health and social welfare problem within UK society affecting $16 \%$ of under $16 \mathrm{~s}$ to $2 \mathrm{~m}$ children and young people. It is under identified and under reported. Better understanding of the impact on individuals and families by commissioners, health and social care providers only goes part way to resolving the current problems. It is only by recognising the range of presentations, symptoms and the variety of settings in which the presence and impact of sexual violence might reveal itself that statutory and voluntary services can hope to respond appropriately to the needs of individuals. It is the responsibility of individual professionals and local services to ensure that the individual needs of people are met at the right time, by the right people, in the most sensitive way. This paper uses recent evidence relating to prevalence, incidence and the impact of sexual violence against children. In particular it identifies the ways in which the NHS can effectively respond to the physical and psychological needs of children young people and their families to ensure that health services are age appropriate, timely, provided in an environment which is supportive and by knowledgeable staff. 